\title{
A Case of Next-generation Sequencing Gene Testing: Points to be Considered in Testing and Reporting
}

\author{
Na-Kyoung Kim (i), Dr. Jur. ${ }^{1}$ and Jong-Won Kim (), M.D. ${ }^{2}$ \\ ${ }^{1}$ College of Law, Sungshin Women's University, Seoul, Korea; '2Department of Laboratory Medicine and Genetics, Samsung Medical Center, Sungkyunkwan \\ University School of Medicine, Seoul, Korea
}

\section{Dear Editor,}

Although the application of next-generation sequencing (NGS) testing in clinical practice is rapidly increasing, clear testing and reporting process guidelines are lacking in Korea. We report the case of a patient with hypertrophic cardiomyopathy (HCM) who was found to harbor a PSEN2 variant. We focus on new ethics problems that arose as a result of genetic testing, revealing a variant that was analyzed, but not discussed with the patient. This study was reviewed and approved by the Institutional Review Board of Sungshin Women's University and exempted from obtaining written informed consent in accordance with the Korean Bioethics and Biosafety Act (SSWUIRB-2020-044).

A 50-year-old man experienced regular chest discomfort without syncope in 2011. He was transferred from a local clinic, and the date of symptom onset was not clear. None of his six siblings had experienced any heart-related symptoms, but his mother had died from a heart attack in her 50s. The exact time and cause of his father's death were unknown. Through various diagnostic testing, including electrocardiogram (ECG), 24-hour ECG, heart magnetic resonance imaging, and echocardiography, the patient was clinically diagnosed as having HCM. For diagnosis using gene testing, the clinic requested the laboratory to perform NGS testing for HCM. However, for NGS testing, the laboratory used a 49-gene panel for dilated cardiomyopathy (DCM)-related genes in addition to a 32-gene HCM panel. While no candidate pathogenic variant was found using the HCM panel, the DCM panel revealed a candidate variant, c.141G >A (p.Trp47*), in PSEN2 [1]. PSEN2 variants are known to be associated with early-onset familial Alzheimer's disease (AD) [2, 3].

The first question is whether an extension of the testing range in the wet test is justified. Additional testing for DCM can be justified if presumptive consent is recognized [4]. In this case, presumptive consent could have been assumed if the medical relationship between HCM and DCM had been established and if it was clear that the patient would have agreed with testing had he known the association between the diseases [5]. HCM and DCM overlap not only in phenotype but also in causative genes. Representative overlapping genes include MYH, TNNT2, TNNC1, and TNNI3. Moreover, all genes related to HCM are increasingly included for genetic testing of DCM [6]. The diagnostic yield of HCM and DCM gene testing is approximately $30 \%-60 \%$ and $15 \%-25 \%$, respectively [7]. Thus, there is room for the recognition of the medical relationship between HCM and DCM.

At the stage of bioinformatics testing, the question of reporting a PSEN2 variant as a cause of HCM arises. Even if DCM testing is justified, this seems to be unacceptable, because there is currently no evidence of PSEN2 variants causing HCM. According to the guidelines of the European Society of Human Genetics-
Received: January 4, 2021

Revision received: May 28, 2021

Accepted: September 13, 2021

Corresponding author: Jong-Won Kim, M.D.

Department of Laboratory Medicine and Genetics, Samsung Medical Center, Sungkyunkwan University School of Medicine, 81 Irwon-ro, Gangnam-gu, Seoul 06351, Korea

Tel.: +82-2-3410-2705, Fax: +82-2-3410-2719

E-mail: kimjw@skku.edu 
EuroGentest, "only genes with a known (i.e., published and confirmed) relationship between the aberrant genotype and the pathology should be included in the analysis" [8]. Similarly, according to the American College of Medical Genetics and Genomics (ACMG), in the case of most genes other than the 61 genes listed in the guideline, "only variants that have been previously reported and are a recognized cause of the disorder (...) should be reported" $[9,10]$. This criterion concerns the range of information "the laboratory should report to the doctor." However, if the genetic variant in question does not meet these criteria, the issue of reporting to the patient needs no further discussion.

Apart from reporting the PSEN2 variant as a cause of DCM, there is another problem with the reporting of the PSEN2 variant for AD. PSEN2 variants are widely known to be associated with familial $A D$ and account for $5 \%$ of the total early-onset familial $A D$ cases [2, 3]. In this case, it would be desirable not to inform the patient that the PSEN2 variant may be significant for AD. When a patient has not been given an opportunity to choose the disclosure of unsolicited findings and when disease treatment or prevention is not available, it is desirable not to inform the patient about the discovery of the variant. In support of this, ADrelated genes are not included in the list of genes recommended by the ACMG for mandatory testing and reporting $[9,10]$.

We conclude this letter with a reminder that there are no legal or official clinical guidelines for NGS testing in Korea such as those suggested by the ACMG or EuroGentest. We hope that ethics guidelines and a legal framework for comprehensive genetic communication for NGS testing are prepared in the near future.

\section{ACKNOWLEDGEMENTS}

None.

\section{AUTHOR CONTRIBUTIONS}

Kim NK analyzed the data and wrote the manuscript. Kim JW contributed to the study design and agreed to be accountable for all aspects of the work.

\section{RESEARCH FUNDING}

This work was supported by a Sungshin Women's University Research Grant of 2018.

\section{ORCID}

Na-Kyoung Kim https://orcid.org/0000-0002-0961-5875

Jong-Won Kim https://orcid.org/0000-0002-0708-9242

\section{REFERENCES}

1. Li D, Parks SB, Kushner JD, Nauman D, Burgess D, Ludwigsen S, et al. Mutations of presenilin genes in dilated cardiomyopathy and heart failure. Am J Hum Genet 2006;79:1030-9.

2. Levy-Lahad E, Wijsman EM, Nemens E, Anderson L, Goddard KA, Weber JL, et al. A familial Alzheimer's disease locus on chromosome 1. Science 1995;269:970-3.

3. Cacace R, Sleegers K, van Broeckhoven C. Molecular genetics of earlyonset Alzheimer's disease revisited. Alzheimers Dement 2016;12:73348.

4. Korean Supreme Court 2014 da 22871 (Oct 29, 2015, decided). Korean Supreme Court 2001 da 27449 (Jan 11, 2011, decided). https:// www.law.go.kr/precSc.do?menuld=7\&subMenuld=47\&tabMenuld=213 \&query $=2014 \% E B \% 8 B \% A 422871 \#$ licPrec179821 \& https://www.law. go. $\mathrm{kr} /$ precSc.do?menuld=7\&subMenuld=47\&tabMenuld=213\&query= 2014\%EB\%8B\%A422871\#licPrec81196

5. Yang MN and Kim JW. Principles of genetic counseling in the era of nextgeneration sequencing. Ann Lab Med 2018;38:291-5.

6. Burke MA, Cook SA, Seidman JG, Seidman CE. Clinical and mechanistic insights into the genetics of cardiomyopathy. J Am Coll Cardiol 2016; 68:2871-86

7. Hershberger RE, Givertz MM, Ho CY, Judge DP, Kantor PF, McBride $\mathrm{KL}$, et al. Genetic evaluation of cardiomyopathy: a clinical practice resource of the American College of Medical Genetics and Genomics (ACMG). Genet Med 2018;20:899-909.

8. Matthijs G, Souche E, Alders M, Corveleyn A, Eck S, Feenstra I, et al. Guidelines for diagnostic next-generation sequencing. Eur J Hum Genet 2016;24:1515.

9. Green RC, Berg JS, Grody WW, Kalia SS, Korf BR, Martin CL, et al. ACMG recommendations for reporting of incidental findings in clinical exome and genome sequencing. Genet Med 2013;15:565-74.

10. Kalia SS, Adelman K, Bale SJ, Chung WK, Eng C, Evans JP, et al. Recommendations for reporting of secondary findings in clinical exome and genome sequencing, 2016 update (ACMG SF v2.0): a policy statement of the American College of Medical Genetics and Genomics. Genet Med 2017;19:249-55.

\section{CONFLICTS OF INTEREST}

None declared. 